\title{
ARTIGO
}

\section{O USO DO ÁBACO NO ENSINO DAS OPERAÇÕES DE ADIÇÃO E SUBTRAÇÃO: UM RELATO DE EXPERIÊNCIA COM ALUNOS DO ENSINO FUNDAMENTAL ${ }^{1}$}

\author{
Alan Raniel Borges Cruz ${ }^{2}$ \\ Gisele de Fátima Teodoro \\ Viviane Aparecida Bonutti
}

\begin{abstract}
RESUMO
O presente trabalho trata-se de uma pesquisa de campo feita em sala de aula. O tema relaciona o uso do ábaco, tratado como material concreto e atividade lúdica para ensino, e sua vantagem para o ensino e a aprendizagem de operações básicas de Matemática. Foram consultados autores como Rizzo (2001), Centurión (2002), Leite (1989), David (1995), dentre outros que apresentam trabalhos com temas relacionados. A equipe de trabalho buscou respaldar-se nos autores supracitados para criar estratégias de trabalho com estudantes de $6^{\circ}$ ano, com idade entre 10 e 11 anos e verificar se "O uso do ábaco facilita a compreensão das operações básicas de adição e subtração?" e se "É viável o uso do ábaco nas salas de aula?". Utilizaram-se ábacos abertos para construção de processos operatórios, instigando cooperação e organização dentre o grupo de estudantes pesquisado. Foram feitas observações, anotações, colhidos dados, atividades desempenhadas por eles. Observou-se grande interesse dos estudantes para participar das atividades, o desenvolvimento das habilidades desejadas com o trabalho, concluindo assim, a viabilidade de uso do ábaco em sala de aula e sua relevância para ensino e aprendizagem. Foram geradas reflexões positivas sobre a experiência da pesquisa, ressaltouse como os estudantes podem nos surpreender positivamente ao serem instigados a serem ativos no aprendizado da sala de aula e como o trabalho foi gratificante.
\end{abstract}

Palavras chave: Ábaco. Adição. Subtração. Operações. Ensino.

\section{INTRODUÇÃO}

A ideia da pesquisa surgiu de trabalhos anteriores sobre utilização de material concreto em ensino e aprendizagem de Matemática vindos do curso de graduação e de experiências de integrantes do grupo, da presente pesquisa, em sala de aula. Tais experiências levaram ao interesse em materiais concretos, ao perceber que se o professor utilizar materiais concretos

\footnotetext{
${ }^{1}$ Como citar este artigo: CRUZ, Alan Raniel Borges; TEODORO, Gisele de Fátima; BONUTTI, Viviane Aparecida. O uso do ábaco no ensino das operações de adição e subtração: um relato de experiência com alunos do ensino fundamental. ForScience: revista científica do IFMG, Formiga, v. 7, n. 2, e00649, jul./dez. 2019. DOI: 10.29069/forscience.2019v7n2.e649.
}

${ }^{2}$ Autor para correspondência: Alan Raniel Borges Cruz, e-mail: alan_raniel@yahoo.com.br 
para sua aula embasado em um planejamento prévio de aula, ou sequência didática, o material concreto pode facilitar a aprendizagem e o Ensino da matemática.

Em vista disso, optou-se pelo ábaco, pois é um material simples, passível de formas adaptadas, até mesmo com sucata, e lida diretamente com as operações básicas. Operações essas que são fundamentais para o aprendizado de matemática com as quais os estudantes já devem estar consolidadas no Ensino fundamental II, mas nem sempre é a realidade das escolas.

O trabalho desenvolvido se baseia em Rizzo (2001) que cria argumentos sobre ser vantajoso o uso do material concreto para o Ensino de matemática, indicando que materiais concretos, jogos e atividades dinâmicas favorecem o pensamento lógico. Centurión (2002) contribuiu fortemente com esta pesquisa, pois sua obra descreve com riqueza sistemas de numeração, operações e uso do ábaco. Ademais, Barbosa e Gomes (1996) e indicam o estudante como ativo no processo de aprendizagem ao utilizar o material concreto.

Para alcançar o objetivo de analisar se o uso do ábaco facilita a compreensão das operações básicas de adição e subtração, e se é viável seu uso nas salas de aula, o grupo de pesquisa foi para campo e realizou um trabalho com nove estudantes do $6^{\circ}$ ano do Ensino Fundamental de uma escola da região metropolitana de Belo Horizonte.

\section{POR QUE UTILIZAR MATERIAL CONCRETO?}

Leite (1989, p. 3) discute diversas ideias de Piaget, entre as quais a que "as crianças não devem ser ensinadas, mas, serem levadas a aprender partindo de experimentações sobre situações concretas". O "não ensinar" não significa deixar as crianças sem orientação, mas sim, que o professor deve fazer a condução das atividades sem deixar de dar espaço para que ela se expresse. É criar um ambiente de interação e de diálogo em sala de aula para que se tenha a troca de ideias, a discussão de significados, o chamado "ambiente de aprendizagem pautado no diálogo" (NACARATO; MENGALI; PASSOS, 2009, p. 81), o que torna a sala de aula um espaço de construção de conhecimento. A construção acontecerá quando o estudante for ouvido ao explicar como opera, de onde parte para chegar à resposta de um problema, ou, descrevendo como liga informações umas às outras em suas estratégias de resolução (SMOLKA, 2007 apud NACARATO; MENGALI; PASSOS, 2009, p. 82).

Partindo das ideias de que o conhecimento é construído e de que as crianças aprendem com situações que lhe possibilitem serem sujeitos atuantes, diz-se que usar o material 
concreto como uma ferramenta de ensino e aprendizagem é possível, pois, com ele se oportuniza ao estudante várias ações ativas como jogar, manusear, fazer testes, verificar processos. Pode-se ver isso com a fala de Barbosa e Gomes (1996):

[...] o estudante, ao jogar ou lidar com material concreto, passa a ser um elemento ativo de seu processo de aprendizagem, deixando de ser um ouvinte passivo das explicações do professor, porque tem a oportunidade de vivenciar a construção de seu conhecimento. [...] Ao jogar ou trabalhar com material concreto, os estudantes analisam os resultados e, se necessário, reformulam hipótese e realizam novas verificações através de outras tentativas. A cada instante, usam as conclusões anteriores e novas hipóteses e isso se repete até que se convençam de que descobriram a estratégia certa. Esse processo [...] compõe o raciocínio lógico que é uma das metas principais do Ensino de Matemática (p. 92-93).

O trecho apresenta várias ações ativas possíveis com o uso de material concreto, além disso é possível ressaltar a importância de utilizar material concreto coma fala de Rizzo (2001, p. 31)

O objetivo de qualquer educação deve ser o de levar a criança a regular suas ações
voluntariamente. Isso não quer dizer que ela tenha uma licença limitada de ação, ao
contrário, num ambiente de trabalho diversificado livre. Ela tem os limites impostos
e cobrados pelo grupo. Somente o trabalho diversificado livre exercita a opção,
oferece espaço à discussão de idéias [SIC], valores e opiniões, e impõe limites
naturais gerados pelas necessidades e desejos do grupo pondo a criança em
constante reconhecimento e avaliação dos resultados de sua ação física e social.

Rizzo (2001, p. 34), em seu texto, explicita algumas vantagens do uso do material concreto para o ensino de matemática. Ela relaciona o uso de materiais concretos e atividades lúdicas diretamente com o fortalecimento do pensamento e afirma, ainda, que os jogos e exercícios de desafio contribuem mais para o pensamento e aprendizado de matemática (não somente de matemática) do que os exercícios com apenas certo e errado, aqueles exercícios que possuem respostas muito diretas sem problematização. Quando a atividade envolve jogos e brincadeiras, pode-se chamá-la de atividade lúdica (AULETE, 2009, p. 501), ou ainda, quando inserir ações de divertimento, manuseio de objetos e uso da imaginação.

Ainda segundo Rizzo (2001),

É a atividade lúdica que alia ao prazer, que deve predominar na maioria das atividades oferecidas à infância, seguida das atividades criadoras, realizadas através das artes, que estimulam organizações e construção do pensamento e expressão de idéias [SIC]. [...] É importante ressaltar que todo material oferecido para o trabalho de arte, assim como para os jogos, deve ser de uso coletivo, a fim de tornar possível a realização do trabalho diversificado de livre escolha. A educação que partilha materiais também partilha regras de uso, proporcionando assim a necessária formação moral-social e a noção de bem comum, indispensáveis a uma sociedade que se deseja democrática (p. 32 e 33 ) 
A fala de Rizzo (2001) reafirma a importância do estudante ativo no processo. O próprio ato de partilhar seu material concreto durante a aula tem a importância de uma ação social que irá influenciar positivamente na formação cidadã do estudante. De forma análoga, David (1995) fala sobre o processo de Ensino, e como deve haver comprometimento com as transformações sociais no processo de modo a tornar o estudante participante ativo do seu aprendizado. Deve haver a troca constante de papéis de aprender e ensinar entre professor e estudante no processo. Essa troca de papéis acontece quando o estudante conta para o professor ou para os colegas como conseguiu resolver um problema proposto, ou também, quando consegue relacionar o conteúdo da aula com sua vida prática, alguma situação vivida, ou contexto que ele conheça.

Outro ponto citado por David (1995) é a extrapolação das habilidades de matemática, que deve existir fazendo com que o foco das aulas e atividades não se restrinja ao conteúdo em si, procurando ampliá-lo com outros, de forma interdisciplinar dar contexto em outras áreas curriculares, recomendação feita, inclusive, nos Parâmetros Curriculares Nacionais PCN de matemática (BRASIL, 1997a, p. 37)

A extrapolação do conteúdo também acontece ao se relacionar com temas transversais ${ }^{3}$, e principalmente situações vividas pelos estudantes, "é essencial que se conheça não apenas o que se ensina, mas para quem se ensina" (MINAS GERAIS, 2005, p. 12), pois uma das finalidades do ensino de matemática é levar o estudante a compreender e transformar o mundo a sua volta (BRASIL, 1997a, p. 37), ele não irá compreender a relação da aula e do seu mundo se esse mundo não aparecer na aula.

A Matemática pode ser utilizada para explicação, compreensão e análise da nossa prática social, quando o estudante a instrumentaliza, ele pode ser capaz de propor alterações em seu meio social, isso ocorre principalmente nos anos iniciais do Ensino fundamental e até o $6^{\circ}$ ano, onde a matemática ainda é muito prática e requer poucas abstrações da realidade. As operações básicas são fáceis de serem relacionadas com uma situação de compras no supermercado, numa loja, divisão de itens entre colegas, noções de quantidade usadas em receitas, o aprendizado de distancias, tempo, tudo está muito relacionado ao mundo real.

\footnotetext{
${ }^{3}$ Os Parâmetros Curriculares Nacionais incorporam [...] no currículo de forma a compor um conjunto articulado e aberto a novos temas, buscando um tratamento didático que contemple sua complexidade e sua dinâmica, dando-lhes a mesma importância das áreas convencionais. O currículo ganha em flexibilidade e abertura, uma vez que os temas podem ser priorizados e contextualizados de acordo com as diferentes realidades locais e regionais e outros temas podem ser incluídos. O conjunto de temas aqui proposto (Ética, Meio Ambiente, Pluralidade Cultural, Saúde e Orientação Sexual) recebeu o título geral de Temas Transversais.[...] (BRASIL, 1997b, p. 25)
} 
O recurso de utilizar a matemática para compreender a vida prática e tomar decisões, remete a Millar (2003, p. 5), que descreve a importância do Ensino de ciências e da compreensão de tecnologias. Para esse autor, sob o "argumento da utilidade" (MILLAR, 2003, p. 150), as pessoas com mais conhecimento estão mais preparadas para tomar decisões em atividade simples que sejam, como fazer uma dieta, avaliar propagandas, fazer escolhas com sensatez enquanto consumidores.

\section{SISTEMA DE NUMERAÇÃO INDO ARÁBICO E O ÁBACO}

Um sistema de numeração é "Um conjunto de símbolos e regras utilizado para escrever números [...]” (CENTURIÓN, 2002, p. 21). A origem do Ábaco está ligada intimamente ao sistema de numeração Indo-arábico, "Indo" por ter sido criado pelos indianos, “arábico" por ter sido aperfeiçoado pelo povo árabe. Atualmente é o sistema de numeração mais utilizado, está presente nas mais diversas culturas. Tal sistema funciona de forma decimal, ou seja, na base dez. Algumas vezes é referido também como sistema de numeração decimal (CENTURIÓN, 2002, p. 32)

Os símbolos do sistema Indo-arábico passaram por várias transformações, conforme o Quadro 1:

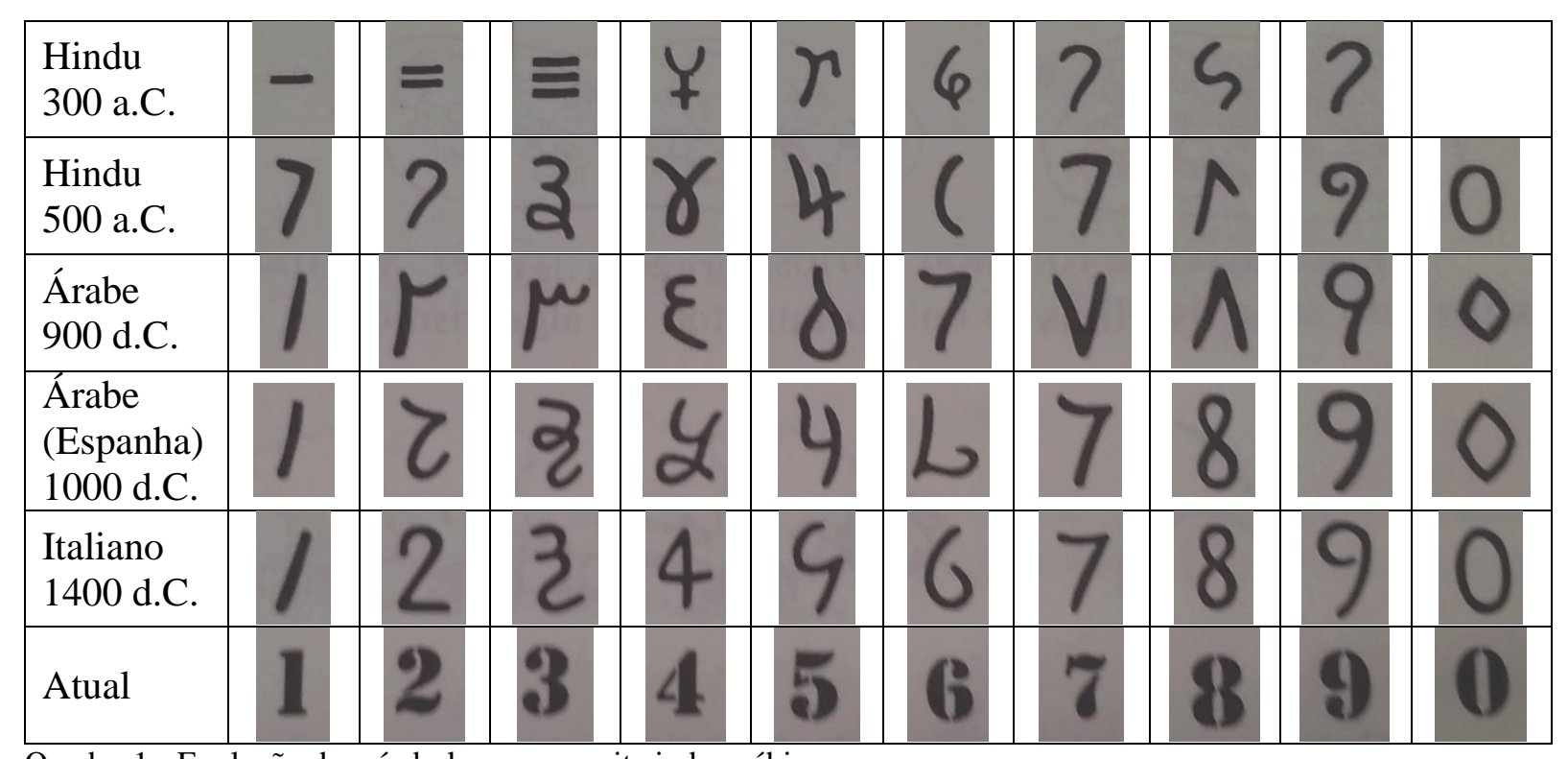

Quadro 1 - Evolução dos símbolos para escrita indo-arábica.

Fonte: (CENTURIÓN, 2002, p. 33)

Os sistemas anteriores ao indo-arábico possuíam alguns pontos a serem melhorados, 
não era possível utilizar os mesmos símbolos para representação e cálculos de forma prática ou simples. O ábaco foi inventado para tentar contornar as dificuldades de cálculo em sistemas de numeração antigos, ele é considerado, dentre as máquinas de calcular, uma das mais antigas (CENTURIÓN, 2002, p. 36, 41)

O sistema indo-arábico tornou os anteriores ultrapassados justamente por permitir fazer cálculos com os próprios símbolos que representavam os números. E também, pois utilizando-o, podemos escrever qualquer número imaginável, algo que não era possível com outros sistemas de numeração. Os números romanos, por exemplo, são muito complexos para cálculos, logo, os cálculos eram feitos com o ábaco nas sociedades que os adotavam como padrão (CENTURIÓN, 2002, p. 36, 41)

Por volta do século XIII, um grande matemático, Leonardo de Pisa (1175-1240), também conhecido com Fibonacci, escreveu um tratado de aritmética que explicava detalhadamente e organizadamente o sistema indo-arábico e suas regras de cálculo. Esse tratado foi denominado Liber abaci, que significa 'tratado do Ábaco' embora, na verdade não fosse um tratado sobre o cálculo no Ábaco, mas ao contrário, ensinasse métodos e processos de se calcular através dos numerais indo-arábicos (CENTURIÓN, 2002, p. 42).

É possível então indicar que em sua origem, o ábaco, muitas vezes, era uma das únicas formas práticas de realizar um cálculo. Diferente dos sistemas de numeração, o ábaco permanece basicamente o mesmo em essência desde sua criação, e é basicamente o conjunto de regras para representar números. O que pode sofrer variação são seus formatos, no que se relaciona aos materiais para confeccioná-lo; versões iniciais utilizando areia, depois pedras, bandejas de areia, dentre outras. Vale lembrar que o ábaco é usado para fazer cálculos, que é uma palavra de origem no latim, calculus, significando "pedra" (CENTURIÓN, 2002, p. 41). Conforme Dantzig ${ }^{4}$ (p. 28) traduzido e citado por Centurión (2002, p. 41) “a origem da palavra não é certa. Alguns a remontam as semita $a b a c$, poeira: outros acreditam que vem do grego abax, placa".

Atualmente o uso do ábaco não se faz necessário para um cálculo como aconteceu no passado. Sua principal utilidade atual acontece nas aulas de matemática, facilitando compreensão do sistema decimal e proporcionando uma abordagem concreta da representação de números, e também auxiliando nas operações de adição e subtração. De acordo com Centurión (2002, p. 43), a utilização do ábaco é adequada, ”[...] pois podemos reproduzir a

\footnotetext{
4 "The origin of the word abacus is not certain. Some trace it to the Semitic abac, dust; others believe that it came from the Greek abax, slab." (DANTZIG, 2005, p. 28). Dantzig, Tobias. Number the language of science. Edited
} 
tentativa dos antigos hindus de traduzir a ação do ábaco na linguagem dos numerais". Utilizar o ábaco na aula de matemática é lançar mão de uma estratégia para levar o estudante a como o processo das operações de adição e subtração foi criado para, assim, compreender melhor esse processo.

\section{OPERAÇÕES BÁSICAS COM NÚMEROS NATURAIS UTILIZANDO O ÁBACO}

O ábaco permite ao estudante visualizar as operações que estão efetuando. Aquela frase, tão usada nos anos iniciais, "vai um” toma sentido com o uso dele, para isso, optou-se pelo trabalho com o ábaco aberto em uma de suas extremidades, pois ele permite, com liberdade, que sejam adicionadas ou retiradas suas peças.

A expressão "vai um" indica que, ao fazer uma adição, alguma ordem alcançou mais do que nove elementos. Com isso, dez elementos dessa ordem devem ser retirados e representados na próxima ordem como apenas um. Quando se diz "pegar emprestado" significa que, ao efetuar uma subtração, o valor do subtraendo em determinada ordem é superior ao do minuendo, logo vai ser necessário retirar um elemento da classe posterior daquela do minuendo que está sendo trabalhada, para acrescentar dez e poder continuar a subtração.

Para fazer cálculos, primeiramente o estudante deve saber representar qualquer número proposto e possível no ábaco. É importante estipular uma ordem a ser seguida. $\mathrm{O}$ ideal é representar as ordens de forma crescente da direita para a esquerda do estudante, e deixar claro que, em cada haste, não pode haver mais do que nove peças de representação.

A Figura 01expõe como são representados alguns números no ábaco.
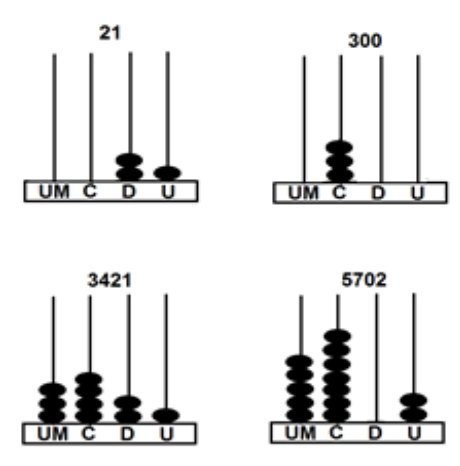

Figura 01 - Representações de números naturais no Ábaco.

Fonte: Os autores.

by Joseph Mazur, Foreword by Barry MazurNew York: Pi Press. The Masterpiece Science Edition, 2005. 
Uma vez que se saiba representar um número natural qualquer no ábaco, partindo do pressuposto que existem hastes suficientes para a representação, pode-se então partir para as operações. A operação de adição está ligada à ideia de juntar, acrescentar. "Sendo a, b e c números naturais quaisquer, a sentença matemática que traduz esta operação é: $a+b=c$ onde, a e b são parcelas da adição e c é a soma” (CENTURIÓN, 2002, p. 90).

Para adicionar, basta representar dois números e juntar suas peças, respeitando se a peça representa unidade, dezena, centena, milhar, e então, juntar apenas as que representam as unidades com as unidades, as dezenas com as dezenas e assim por diante. Num momento inicial, pode ser interessante utilizar dois ábacos. Com a regra de não poder acumular dez peças numa mesma haste, existe uma ajuda ao estudante para se atentar para o característico "vai um", ou seja, ele vai perceber que aquela haste, representando unidade, por exemplo, não pode mais receber peças até que algo seja feito, que, no caso, é retirar dez unidades e mover uma peça para a próxima haste. E o principal, entender que a tal peça movida está representando dez de sua posição anterior.

Já a subtração está ligada às ideias de tirar, comparar e completar. Suponha a, b e c números quaisquer, a operação matemática pode ser representada como: $\mathrm{a}-\mathrm{b}=\mathrm{c}$. Denominando a como minuendo, b como subtraendo, por fim, c como resto ou diferença (CENTURIÓN, 2002, p. 93-94)

A subtração será efetuada ao representar um número e depois retirar a quantidade necessária do subtraendo. Com o ábaco, fica fácil para o estudante entender o que é o "pegar emprestado". Pois quando não for possível retirar todas as peças necessárias, o estudante terá que pegar uma emprestada na haste posterior para poder substituir por dez na que está operando e, assim, concluir o cálculo. Lembra-se que, nesse momento, os estudantes questionam sobre poder ter mais do que nove numa haste, basta ter em mente que aquele número não é definitivo, é só uma estratégia para operar.

\section{DESENVOLVIMENTO DA PESQUISA}

O grupo de trabalho teve várias experiências com uso de material concreto para ensino e aprendizagem durante a graduação em Matemática. Devido ao fato de que os trabalhos sempre aconteceram com materiais diversos, decidiu-se escolher apenas um e focar a pesquisa nele. Diante das experiências em sala de aula, foi possível perceber que vários alunos, já no Ensino fundamental II ( $6^{\circ}$ ano), possuem dificuldades básicas, desde valor relativo dos 
algarismos até as operações de adição e subtração.

Feitos o levantamento bibliográfico e os estudos norteadores para prática, o próximo passo foi o trabalho em campo com o intuito de responder às seguintes perguntas: "O uso do ábaco facilita a compreensão das operações de adição e subtração?" e "É viável o uso do ábaco nas salas de aula?".

Trabalhou-se com nove estudantes do $6^{\circ}$ ano do Ensino fundamental em uma escola municipal na cidade de Contagem, região metropolitana de Belo Horizonte. Nenhum dos pesquisadores era professor das turmas envolvidas na pesquisa. Os primeiros contatos entre eles e os estudantes foram feitos na aplicação da pesquisa. Um dos integrantes do grupo trabalhava na escola onde esse estudo aconteceu e a pedagoga, em exercício na escola, foi quem sugeriu que o estudo se realizasse com a turma de $6^{\circ}$ ano.

Sobre os estudantes, nenhum já havia sido reprovado em sua trajetória escolar. Logo, todos possuíam entre 10 e 11 anos, idade correta para frequentar o $6^{\circ}$ ano. Não foi feito um estudo socioeconômico com os mesmos, porém, todos moram nas proximidades da escola. A região é de classe baixa, todavia não é zona de vulnerabilidade ou risco.

A seleção dos estudantes ocorreu através da análise de um teste diagnóstico, em formato de questionário, sobre adição, subtração, decomposição de números e valor relativo/absoluto. Ao todo, a escola possuía três turmas de $6^{\circ}$ ano, todas com aproximadamente 30 estudantes por sala. A pedagoga indicou a turma que apresentava maiores dificuldades em matemática e, então, nessa com 27 estudantes, aplicou-se o teste diagnóstico em 24, presentes no dia estipulado para tal.

O objetivo desse teste diagnóstico foi de identificar os alunos que possuíssem dificuldades em operações básicas (adição e subtração), além de representação numérica e valor posicional. Foram selecionados os estudantes que obtiveram entre $46 \%$ e $60 \%$ de acertos, o que foi considerado pela equipe de pesquisa como notas medianas, pois estudantes com boa pontuação poderiam ter muita facilidade e aqueles com baixa pontuação poderiam ter muita dificuldade na execução dos trabalhos. 12 alunos foram selecionados.

De posse das autorizações dos responsáveis para a participação dos alunos, e organizados os horários e a dinâmica para utilização do espaço da escola após o horário de aulas do turno da manhã, firmou-se o compromisso de trabalhar com nove alunos, já que os responsáveis por três deles não autorizaram a participação por questões de compromissos de horários.

Ao todo, foram feitos nove encontros com os estudantes, não contando o encontro em 
que os pesquisadores foram à turma fazer a seleção. Esses encontros aconteciam após o horário de aula, nas terças e quintas-feiras, durante o final da primeira etapa de avaliação da escola, meses de abril e março. Os responsáveis pelos estudantes foram avisados, para concordar ou não com o trabalho combinou-se como se fossem aulas de reforço em matemática. Como o turno de estudo terminava às 11:30 h da manhã, a escola, com muitos préstimos, oferecia alimentação para que os estudantes não necessitassem ir para casa e retornar. A ação facilitou muito em questão de organização de horários, frequência e participação do público alvo. O trabalho iniciava-se às 12:00 e era encerrado às 12:55, antes da entrada do próximo turno de aulas da escola.

Foi feita a disponibilização de uma sala própria para o trabalho. Esta possuía quadro para anotações, cadeiras e mesas, em bom estado, suficientes para todos. Era de fácil acesso aos bebedouros e banheiros, além de ser bem arejada. Por não ser um momento de aula na escola, o ambiente era silencioso e sem interferências externas no trabalho.

Existem diferentes tipos de ábacos, alguns até confeccionados com materiais acessíveis, como EVA, cartolina, palito de picolé, latinhas, etc. O ábaco utilizado na pesquisa de campo foi feito de madeira, possui base com quatro hastes classificadas da direita para esquerda como unidades, dezenas, centenas e unidades de milhar.

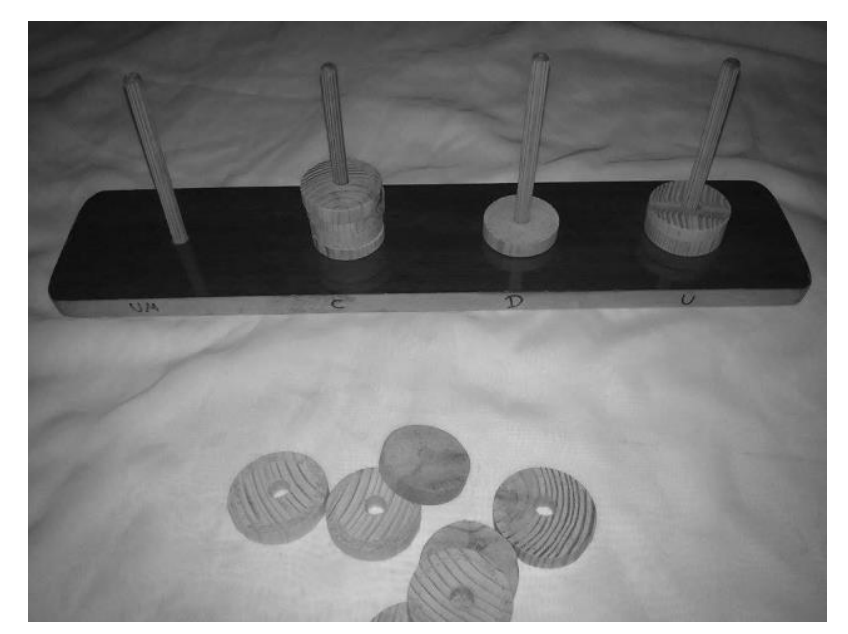

Figura 02 - Modelo de Ábaco utilizado no trabalho.

Fonte: Os autores.

No primeiro contato com os estudantes, o ábaco foi apresentado ainda com instrumentos provisórios diferentes dos que foram utilizados no restante da pesquisa, devido a atrasos na confecção do material ideal. O grupo de pesquisa contou a história do ábaco para os alunos e, em seguida, fez uma explicação sobre o posicionamento das peças, pois o ábaco em 
questão é dividido em classes de valores, ou seja, unidades, dezenas, centenas e unidades de milhar. Com isso, foi possível trabalhar a decomposição e representação de números.

Nos dois encontros seguintes, foram trabalhadas, respectivamente, adição e subtração, ambas mais simples, com cálculos que não necessitassem usar "vai um" ou "pegar emprestado". Trabalhou-se, no quarto e quinto momentos, a adição com mais complexidade, resolvendo operações em que foi necessário utilizar o "vai um”. O sexto, o sétimo e o oitavo encontros foram focados no trabalho com subtração utilizando a ideia de "pegar emprestado", o que se mostrou ainda mais complexo.

As aulas seguiam o roteiro de iniciar contando algum pequeno caso, narrando uma situação problema. Em seguida, era entregue a eles o material, atividades oferecidas através de xerox, com os problemas escritos para identificarem os números e, em seguida, fazer a representação em seus ábacos. Uma vez representado o primeiro número, precisavam conseguir indicar se a operação era de adição ou subtração para iniciar o cálculo. Como erámos três facilitadores (o grupo de pesquisa) para nove estudantes, posteriormente oito, foi fácil dividir a atenção e acompanhá-los em cada dúvida.

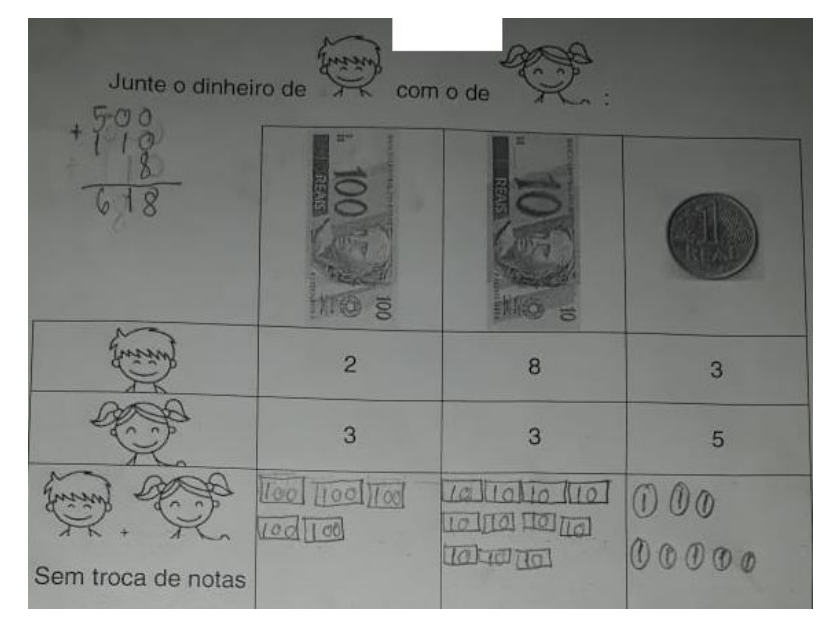

Figura 03 - Exemplo de problema trabalhado.

Fonte: Adaptado de Imenes, Jakubovic e Lellis (2000, p. 97).

Na Figura 03, aparece um problema em que as notas e moedas representam unidades, dezenas e centenas. Cada etapa de representação foi feita em desenho e no ábaco com os estudantes. Em seguida, deveria fazer a mesma operação, porém, com a troca de notas, restando apenas uma nota nas dezenas, as outras dez foram representadas como apenas uma nas centenas. A atividade completa se encontra em anexo. 


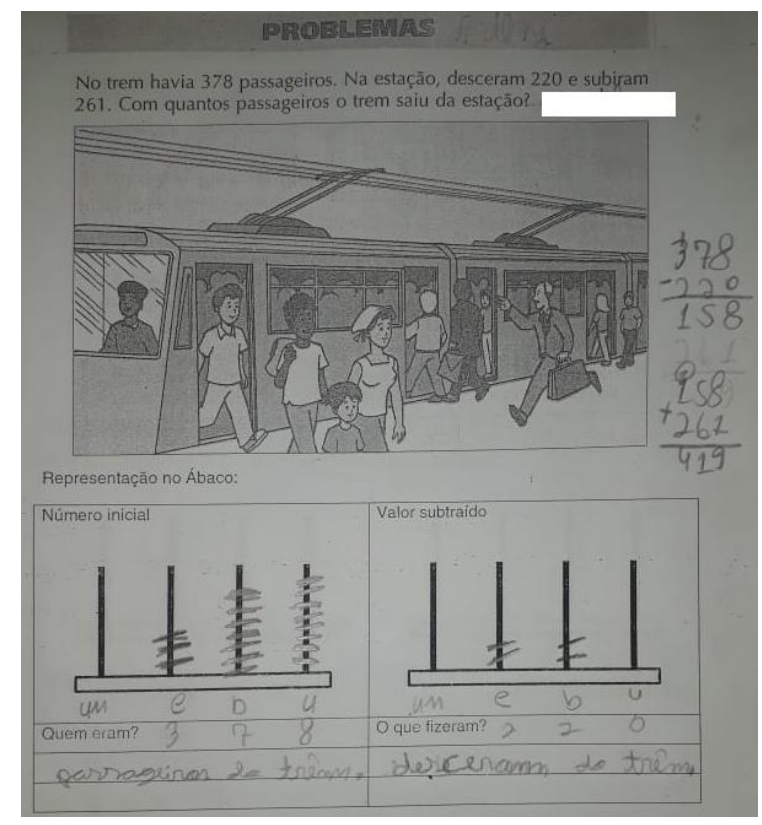

Figura 04- Exemplo de problema trabalhado com registro da representação no Ábaco Fonte: Adaptado de Imenes; Jakubovic; Lellis (2000, p. 99).

Foi muito importante passar a fazer o registro da representação do ábaco também no papel. A partir do momento em que essa prática foi adotada, os estudantes passaram a consultar seus materiais e a modelar e resolver os problemas e operações mais rapidamente. Nos encontros finais, eles já não consultavam as anotações, porém mantiveram o ritmo positivamente.

Inicialmente sentavam de forma individual. Conforme a necessidade da equipe pesquisadora, os estudantes eram organizados em grupos de três, tanto para facilitar a assistência, quanto para compartilhar o ábaco com quatro hastes. Contava-se com 12 ábacos, porém, por erro do profissional que os confeccionou, nem todos possuíam a quarta haste para usar a unidade de milhar, assim compartilhavam o mesmo instrumento para fazer tal uso. Esse trabalho ocorreu de forma muito saudável e com muita disposição entre os alunos para se ajudarem nas operações. Porém uma das alunas, a que abandonou as atividades, não mostrou ânimo em trabalhar em grupo nem em cooperar para aguardar sua vez de ter as dúvidas atendidas.

As anotações eram feitas nos próprios cadernos dos estudantes. Pediu-se um caderno separado, apenas para não gerar possíveis confusões com as atividades da sala de aula, mas poderia ser um caderno usado, desde que tivesse folhas em branco. Algumas vezes, foi necessário fornecer folhas para que utilizassem, mas não houve prejuízo ao trabalho essa 
questão de materiais para anotações.

Uma análise qualitativa simples foi feita a todo instante, tendo como base as dúvidas, as atitudes e as expressões dos alunos: todos estavam interessados e admirados com o seu "novo" instrumento de calcular. Nos primeiros encontros, eles ficavam muito entretidos pegando as peças e empilhando, com o tempo, após aprenderem usar, essa prática sumiu. Uma vez concluída a operação, eram feitos os registros com números e indicada a resposta.

Havia um momento para socialização, em que cada um contava sua resposta. O próprio ato de informar o valor obtido na operação já era uma parte muito importante, pois consolidavam a habilidade de leitura de números com três e quatro algarismos. Entre eles, quem encontrava o mesmo valor já comemorava certos de terem acertado. Um dos integrantes do grupo de pesquisa fazia a correção no quadro disponível na sala. Eram feitos sinais de correto nas folhas de registro dos estudantes e dado "Parabéns", mesmo se não acertassem a operação por completo.

E para completar a coleta de dados empíricos, no último contato, aplicou-se novamente um teste diagnóstico. Ele foi idêntico ao primeiro, porém com alterações apenas nas alternativas e números. Buscou-se observar, com o instrumento, o que aconteceu com as habilidades dos estudantes de operar e representar os números após o uso do ábaco, ou seja, se houve diminuição das dificuldades em operações básicas. No último encontro, ainda foi possível fazer as correções e comentários com os estudantes. De posse dos dados, foi feita análise dos resultados englobando todos os instrumentos de pesquisa, anotações feitas pelos pesquisadores, folhas de registros feitas pelos estudantes no decorrer das práticas, anotações referentes às conversas com a professora de matemática dos estudantes pesquisados e com a pedagoga responsável, fotos do desenvolvimento das ações da pesquisa e para então poder tirar as conclusões.

\section{DISCUSSÃO DOS RESULTADOS}

Iniciadas as atividades com o material concreto, foi possível notar grande interesse por parte dos estudantes. Em conversa com a professora de matemática dos estudantes pesquisados, ela os descreveu como agitados e com hábito de dispersão durante a aula, mas no decorrer de todas as atividades do grupo de pesquisa, foi possível observar que não houve agitação incômoda, nem dispersão. Claro, o ambiente era muito diferente e, por isso, acreditase que o trabalho teve grande efeito positivo nos estudantes. Esses efeitos foram observados e 
anotados pelo grupo de pesquisa, são, por exemplo, o comportamento durante a aula da pesquisa, fato que já difere do que foi relatado sobre as aulas regulares de matemática, a qualidade dos registros, questionamentos foram ficando cada vez mais pertinentes, avanços na compreensão e execução das operações de adição e subtração, organização de materiais, cooperação entre eles para realizar as atividades, dentre outros.

Sobre aprenderem a utilizar o ábaco, o avanço dos estudantes foi impressionante. Eles excederam as expectativas iniciais, e foi necessário alterar as atividades programadas, antecipando algumas etapas. Enquanto foi trabalhada representação de números no ábaco, "adição simples", adição com o "vai um" e "subtração simples", as atividades foram desenvolvidas muito rapidamente para acompanhar o ritmo dos estudantes. Indicaram-se os momentos de trabalho com subtração utilizando a ideia de "pegar emprestado" como os de maiores dificuldades.

Durante o processo de fazer o empréstimo na haste posterior, pegar uma dezena para transferir para as unidades, por exemplo, eles confundiam, ao invés de pegar dez para as unidades e continuar a operação, eles pegavam apenas nove e, muitas vezes, perdiam a conta do que já haviam subtraído antes de pegar na próxima haste.

Inicialmente os cálculos eram registrados com muitos pauzinhos. Veja um exemplo na Figura 05, não é um problema, porém para a idade já se faz necessária uma abstração maior, armando a operação desejada.

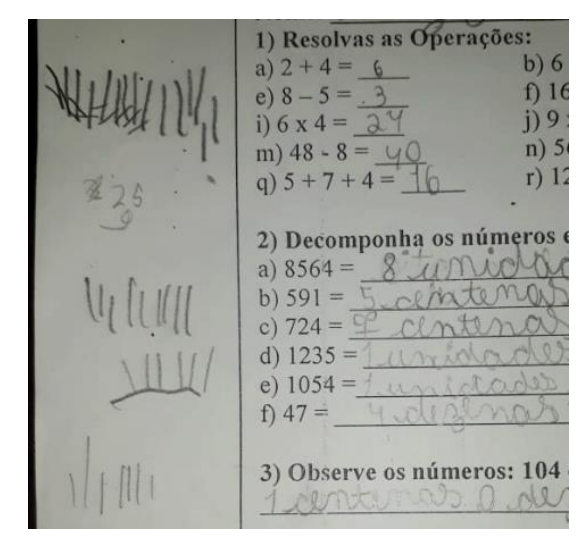

Figura 05 - Operações com pauzinhos. Fonte: Os autores.

Ao final do trabalho, já foi possível verificar que fizeram grandes avanços também nos registros de suas operações, conforme pode-se ver na Figura 06: 


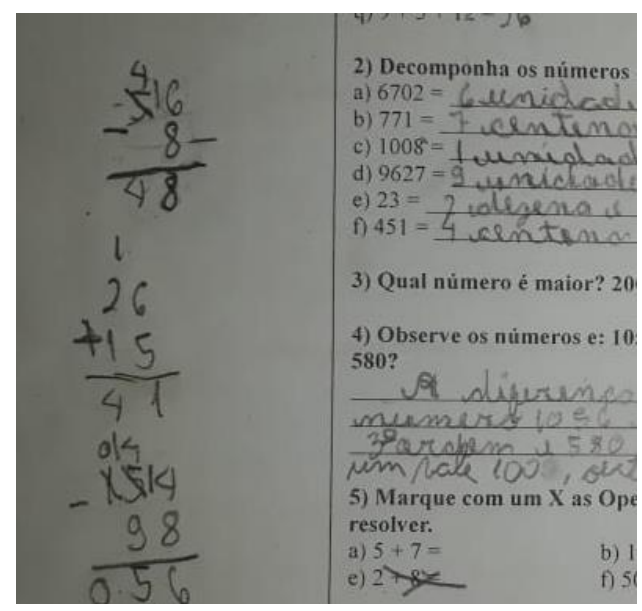

Figura 06 - Operações.

Fonte: Os autores.

$\mathrm{Na}$ conclusão de cada encontro, era questionado aos estudantes se gostaram das atividades e se houve alguma dúvida, eles sempre afirmavam que foi "interessante, divertido, gostaram, ficou mais fácil e entenderam". Vale ressaltar uma exceção, ao alcançarmos o estágio de subtração com o "pegar emprestado", uma aluna afirmou estar muito complicado e desistiu de participar. Houve interesse por parte do grupo em tentar animá-la ao retorno, mas não houve sucesso. Para os estudantes que permaneceram até o final, oito no total, foi feita a comparação entre a nota no primeiro e no segundo teste diagnóstico.

É importe ressaltar que este é um estudo de caso e todas as observações são restritas ao grupo específico. Outros estudantes com contextos e variáveis diferentes poderiam produzir um resultado diferente. Ao final do trabalho de campo, foi observada interação muito satisfatória entre estudantes e ábaco. Tanto no momento inicial, como no decorrer da aplicação.

Durante o levantamento bibliográfico para embasamento do trabalho, foi possível observar afirmações de que o material concreto deve ser trabalhado com uma aula muito bem estruturada para que não perca seu sentido. Fiorentini e Miorim (1990, p. 6) apontam que o material concreto pode ser muito proveitoso em sala, porém o material, por si, não é suficiente. Faz-se necessário um bom planejamento do professor de como vai utilizar tal material, pois o simples uso de jogos ou atividades lúdicas para o ensino de matemática não irá garantir melhor aprendizagem. No decorrer da pesquisa, o grupo pôde vivenciar a potencialidade do uso do ábaco, atribuindo isso ao fato de as aulas terem sido preparadas previamente, e vivenciando a fala dos autores de que a presença do ábaco sozinha não se 
justifica, o professor está ali com o papel fundamental de facilitador da construção de conhecimentos. Foi necessário estar presente em cada etapa e cada dúvida para manter o interesse dos estudantes na atividade. E também foi possível perceber que, com o material concreto, a aula pode fluir tão bem, que ultrapassará o que o professor planejou. Então ao programar uma aula com o uso de tal recurso, é importante fazer planos de muitas atividades, mais do que o que se imagina necessário para ocupar todo o tempo da aula, para não perder o momento mais proveitoso de interação entre estudante e material. Deixar esse momento passar simplesmente por não ter mais atividades ou ações para executar seria um grande desperdício. Notou-se que a partir do momento em que os estudantes compreendem os comandos e acertam a primeira etapa vão se motivando e interessando cada vez mais até o fim da aula.

Conforme citado anteriormente, aplicaram-se dois testes diagnósticos para comparação dos resultados de cada estudante e do grupo como todo. Através dos testes diagnósticos percebeu-se que ainda existe no $6^{\circ}$ ano dificuldade em operações básicas e em valor relativo e absoluto de algarismo. Dentre os estudantes avaliados, 10 acertaram mais de $60 \%$ do teste diagnóstico (apenas uma aluna obteve 100\%); 12 estudantes entre $46 \%$ e $60 \%$, e 2 estudantes entre $31 \%$ e $45 \%$. Os estudantes responderam acreditando que fosse uma atividade avaliativa de sua própria professora. Acredita-se, com isso, que tenham respondido com mais compromisso do que se soubessem que foi uma atividade externa.

No primeiro teste diagnóstico, dentre os estudantes escolhidos para o trabalho, apenas dois acertaram a terceira questão, falando sobre valor relativo e valor absoluto. Já na segunda avaliação, apenas um estudante errou a questão de valor absoluto. Porém seu erro foi de confundir dezena com centena, apenas isso. Esse mesmo estudante no primeiro teste diagnóstico respondeu completamente fora do assunto.

A quarta questão do primeiro teste foi sobre identificar quando é necessário usar o "vai um" e quando se "pega emprestado" para concluir uma operação. No primeiro teste, apenas um dos estudantes selecionados acertou todas as alternativas, existiam seis para serem apontadas. Já no segundo teste diagnóstico, cinco estudantes acertaram essa questão por completo. Os outros três, erraram a mesma parte, não marcaram que a adição de "500 + 500" usaria "vai um”. Na parte de subtração com recurso, todos, exceto um, erraram a mesma questão do teste "f) $5231-121$ =", o entendimento do grupo de pesquisa foi que erraram pela presença da unidade de milhar, mesmo havendo outra questão com o milhar, era apenas uma unidade. 

ábaco no ensino das operações de adição e subtração: um relato de experiência com alunos do ensino fundamental

De um modo geral as notas aumentaram, conforme pode-se ver no Quadro 2.

\begin{tabular}{|c|c|c|c|c|}
\hline ALUNOS & $\begin{array}{c}1^{\circ} \text { TESTE } \\
\text { (porcentagem } \\
\text { de acertos) }\end{array}$ & $\begin{array}{c}2^{\circ} \text { TESTE } \\
\text { (porcentagem } \\
\text { de acertos) }\end{array}$ & $\begin{array}{c}\text { QUESTÃO DE } \\
\text { IDENTIFICAR } \\
\text { ADIÇÃO COM } \\
\text { RESERVA }\end{array}$ & $\begin{array}{c}\text { QUESTÃO DE } \\
\text { IDENTIFICAR } \\
\text { SUBTRAÇÃO COM } \\
\text { RECURSO }\end{array}$ \\
\hline A & 54 & 100 & $\begin{array}{c}\text { ACERTOU } \\
\text { TUDO }\end{array}$ & $\begin{array}{c}\text { ACERTOU } \\
\text { TUDO }\end{array}$ \\
\hline B & 55 & 75 & $\begin{array}{c}\text { ACERTOU } \\
\text { TUDO }\end{array}$ & \multirow{7}{*}{$\begin{array}{l}\text { TODOS ERRARAM } \\
\text { APENAS A ÚLTIMA } \\
\text { QUESTÃO. }\end{array}$} \\
\hline $\mathrm{C}$ & 51 & 72 & $\begin{array}{c}\text { ERROU UMA } \\
\text { ALTERNATIVA }\end{array}$ & \\
\hline D & 60 & 95 & $\begin{array}{l}\text { ACERTOU } \\
\text { TUDO }\end{array}$ & \\
\hline E & 55 & 75 & $\begin{array}{c}\text { ERROU UMA } \\
\text { ALTERNATIVA }\end{array}$ & \\
\hline F & 52 & 80 & $\begin{array}{c}\text { ACERTOU } \\
\text { TUDO }\end{array}$ & \\
\hline G & 46 & 69 & $\begin{array}{c}\text { ERROU UMA } \\
\text { ALTERNATIVA }\end{array}$ & \\
\hline $\mathrm{H}$ & 56 & 70 & ACERTOU & \\
\hline
\end{tabular}

Quadro 02 - Análise dos dados dos dois teste diagnósticos Fonte: Os autores.

Um dos estudantes participantes obteve $100 \%$ de acerto no segundo teste diagnóstico. Quanto aos outros, o mais importante é que, mesmo errando, foi possível observar no segundo teste que pareciam saber melhor o que estavam fazendo, seus erros foram mais próximos das alternativas corretas na questão quatro; suas respostas nas questões abertas foram melhores; os rascunhos deixados ao lado da folha possuíam mais rigor e detalhes que os primeiros.

\section{CONSIDERAÇÕES FINAIS}

Ao final da pesquisa em campo, observou-se que os estudantes envolvidos nas atividades desempenhadas mostraram bastante interesse pelo ábaco e desenvolveram as habilidades relacionadas ao conteúdo que lhes foi apresentado.

Pode-se afirmar ainda que a pesquisa foi de suma importância para o grupo de trabalho, enquanto pesquisadores e professores, pois possibilitou conhecer um pouco mais sobre o ábaco, que apesar de ser um material bastante antigo e de sua eficiência para o ensino das operações básicas, é pouco explorado pelos professores que trabalham com matemática no Ensino fundamental.

Ao cabo da pesquisa, o grupo concluiu que fazer o uso do ábaco em sala de aula é viável, e inclusive, interessante, pois estimula os estudantes a refletirem sobre as operações, já que deixaram de resolver os exercícios de forma mecanizada e passaram a compreender um 
pouco mais de como e porque eles resolvem as operações.

A perspectiva do grupo de pesquisa ao final foi de que este estudo possibilitou refletir sobre os diversos meios que se pode lançar mão para ensinar matemática aos estudantes e como eles podem auxiliar no processo de ensino e aprendizagem, concluindo que o uso do ábaco facilita na compreensão das operações básicas de adição e subtração.

\title{
THE USE OF ABACUS IN THE TEACHING OF ADDITION AND SUBTRATION OPERATIONS: A REPORT OF EXPERIENCE WITH FUNDAMENTAL SCHOOL STUDENTS
}

\begin{abstract}
The present work is a field research done in the classroom, the theme relates the use of abacus, treated as concrete material and playful activity for teaching, to be advantageous for teaching and learning basic mathematical operations. Authors such as Rizzo (2001), Centurión (2002), Leite (1989), David (1995), among others presenting works with related themes were consulted. . The work team sought to build upon the above authors to develop strategies for working with 6th graders aged 10-11 and to verify that "Does the use of abacus make it easier to understand the Basic Addition and Subtraction Operations?" And "Is it possible to use abacus in the classroom?" Open abacus was used to construct operative processes, instigating cooperation and organization among the group of students researched. Observations were made, annotations, data collected, activities performed by them. It was observed great interest of students to participate in the activities, the development of the desired skills with the work, thus concluding the feasibility of using abacus in the classroom and its relevance for teaching and learning. Positive reflections were generated on the research experience, highlighting how students can positively surprise us by being urged to be active in classroom learning and how rewarding the work was.
\end{abstract}

Keywords: Abacus. Addition.Subtraction.Operations. Teaching.

\section{REFERÊNCIAS}

AUletTE, C. Minidicionário contemporâneo da Língua Portuguesa, de acordo com a nova ortografia. Rio de Janeiro: Lexicon, 2009.

BARBOSA, M. G. G.; GOMES, M. L. M. Matemática e escola: volume I. Instituto de Ciências exatas. Departamento de Matemática. Belo Horizonte: UFMG, 1996.

BRASIL. Secretaria de Educação Fundamental. Parâmetros curriculares nacionais: Matemática. Brasília: MEC/SEF, vol. 3, 1997a.

BRASIL. Secretaria de Educação Fundamental. Parâmetros curriculares nacionais: Apresentação dos Temas Transversais e Ética. Brasília: MEC/SEF, vol. 8, 1997b. 
CENTURIÓN, M. Conteúdo e metodologia da matemática: Números e Operações. 2. ed. São Paulo: Scipione, 2002.

DAVID, M. M. M. S. As possibilidades de inovação no Ensino-aprendizagem de Matemática elementar. Revista Presença Pedagógica, Jan./Fev. 1995.

FIORENTINI, D.; MIORIM, M. A. Uma reflexão sobre o uso de materiais concretos e jogos no ensino da matemática. Boletim SBEM. São Paulo. Ano 4, n. 7, jul.ago. 1990.

IMENES, L. M.; JAKUBOVIC, J.; LELLIS, M.. Coleção novo caminho: matemática. $2^{\text {a }}$ série, $1^{\circ}$ grau. São Paulo: Scipione, 2000.

LEITE, A. S. Cores - Furos: material concreto na linha de Piaget. São Paulo: Manole, 1989.

MILLAR, R. Um currículo de ciências voltado para a compreensão por todos. Revista Ensaio. Belo Horizonte: UFMG, 2003. vol 5. n. 2. out.

MINAS GERAIS. Secretaria de Estado de Educação de Minas Gerais. Matemática: ensinos fundamental e médio: proposta curricular. Belo Horizonte: Governo do Estado de Minas Gerais, 2005. Conteúdos Básicos Comuns (CBC).

NACARATO, A. M.; MENGAli, B. L. da S.; PASSOS, C. L. B.. A matemática nos anos iniciais do ensino fundamental. Belo Horizonte: Autentica, 2009.

RIZZO, G. Jogos inteligentes: a construção do raciocínio na escola natural. 3. ed. Rio de Janeiro: Bertrand Brasil, 2001. 


\section{APÊNDICES}

\section{APÊNDICE A - Modelo do primeiro teste diagnóstico}

\section{Nome:}

1) Resolvas as Operações:
a) $2+4=$
b) $6+8=$
e) $8-5=$
f) $16-7=$
i) $6 \times 4=$
j) $9 \times 8=$
m) $48-8=$
n) $56-7=$
q) $5+7+4=$
r) $12+14+6=$

c) $12+15=$

g) $150-97=$

$256+875=$

k) $7+4=$

h) $777-89=$

o) $64-8=$

l) $5+3=$

p) $16-2=$

2) Decomponha os números em unidade, dezena, centena e milhar:

a) $8564=$

b) $591=$

c) $724=$

d) $1235=$

e) $1054=$

f) $47=$

3) Observe os números: 104 e 20. Qual a diferença entre o zero do número 104 e o zero do número 20?

4) Observe as Operações:
a) $14+25=$
b) $2+4=$
c) $28+3=$
d) $523+123=$
e) $27+9=$
f) $1002+19=$
g) $15-10=$
h) $25-9=$
i) $25-25=$
j) $60-0=$
k) $105-17=$
1) $75-8=$

A) Primeiro circule as Operações de Adição onde você usou a ideia do "vai um".

B) E depois marque um $X$ nas Operações de menos onde você precisou "pegar emprestado" para resolver. 


\section{APÊNDICE B - Modelo do segundo teste diagnóstico}

\section{Nome:}

1) Resolva as Operações:
a) $2+7=$
b) $7+9=$
c) $15+26=$
d) $273+947=$
e) $18-14=$
f) $19-8=$
g) $154-98=$
h) $655-78=$
i) $7+8=$
j) $6+9=$
k) $4+8=$
l) $8+8=$
m) $49-7=$
n) $56-8=$
o) $72-9=$
p) $35-5=$

q) $9+5+12=$

2) Decomponha os números em unidade, dezena, centena e unidade de milhar:
a) $6702=$
b) $771=$
c) $1008=$
d) $9627=$
e) $23=$
f) $451=$

3) Qual número é maior? 200 ou $00200 ?$

4) Observe os números e: 1056 e 580. Qual a diferença entre o zero do número 1056 para o zero do 580 ?

5) Marque com um $X$ as Operações onde for necessário usar a ideia de "vai um" ou "mais um" para resolver.
a) $5+7=$
b) $12+29=$
c) $1254+8642=$
d) $526+1000=$
e) $2+8=$
f) $500+500=$

6) Circule as Operações onde for necessário usar a ideia de "pegar emprestado" para conseguir resolver.
a) $15-11=$
b) $78-77=$
c) $1005-200=$
d) $800-8=$
e) $78-9=$
f) $5231-121=$ 
CRUZ, Alan Raniel Borges; TEODORO, Gisele de Fátima; BONUTTI, Viviane Aparecida. O uso do ábaco no ensino das operações de adição e subtração: um relato de experiência com alunos do ensino fundamental

\section{APÊNDICE C- Evolução dos registros dos estudantes}
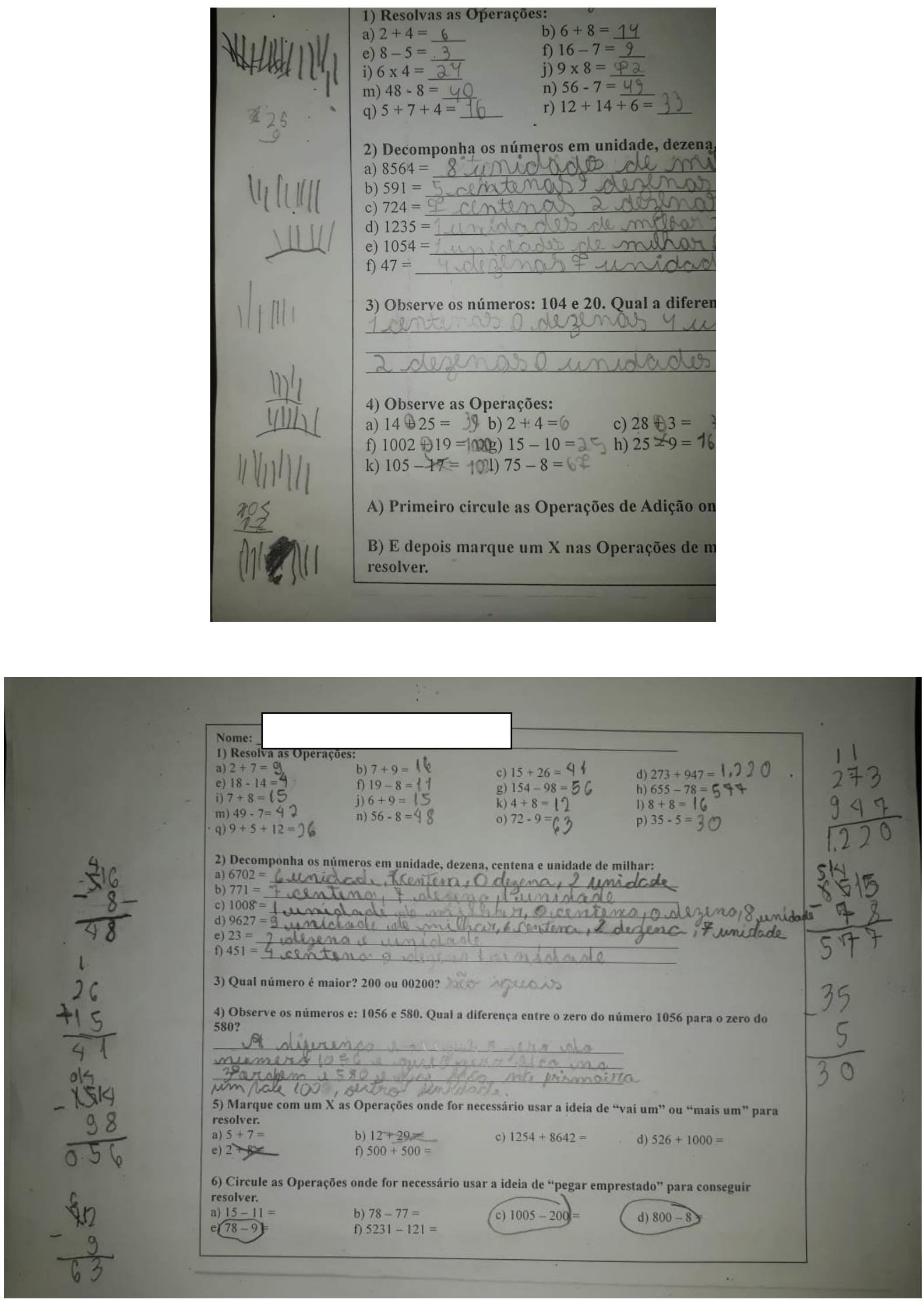

ForSci.: r. cient. IFMG, Formiga, v. 7, n. 2, e00649, jul./dez. 2019 
CRUZ, Alan Raniel Borges; TEODORO, Gisele de Fátima; BONUTTI, Viviane Aparecida. O uso do 23 ábaco no ensino das operações de adição e subtração: um relato de experiência com alunos do ensino fundamental

\section{APÊNDICE D - Exemplos de problemas trabalhados}

\section{Exemplo 1}

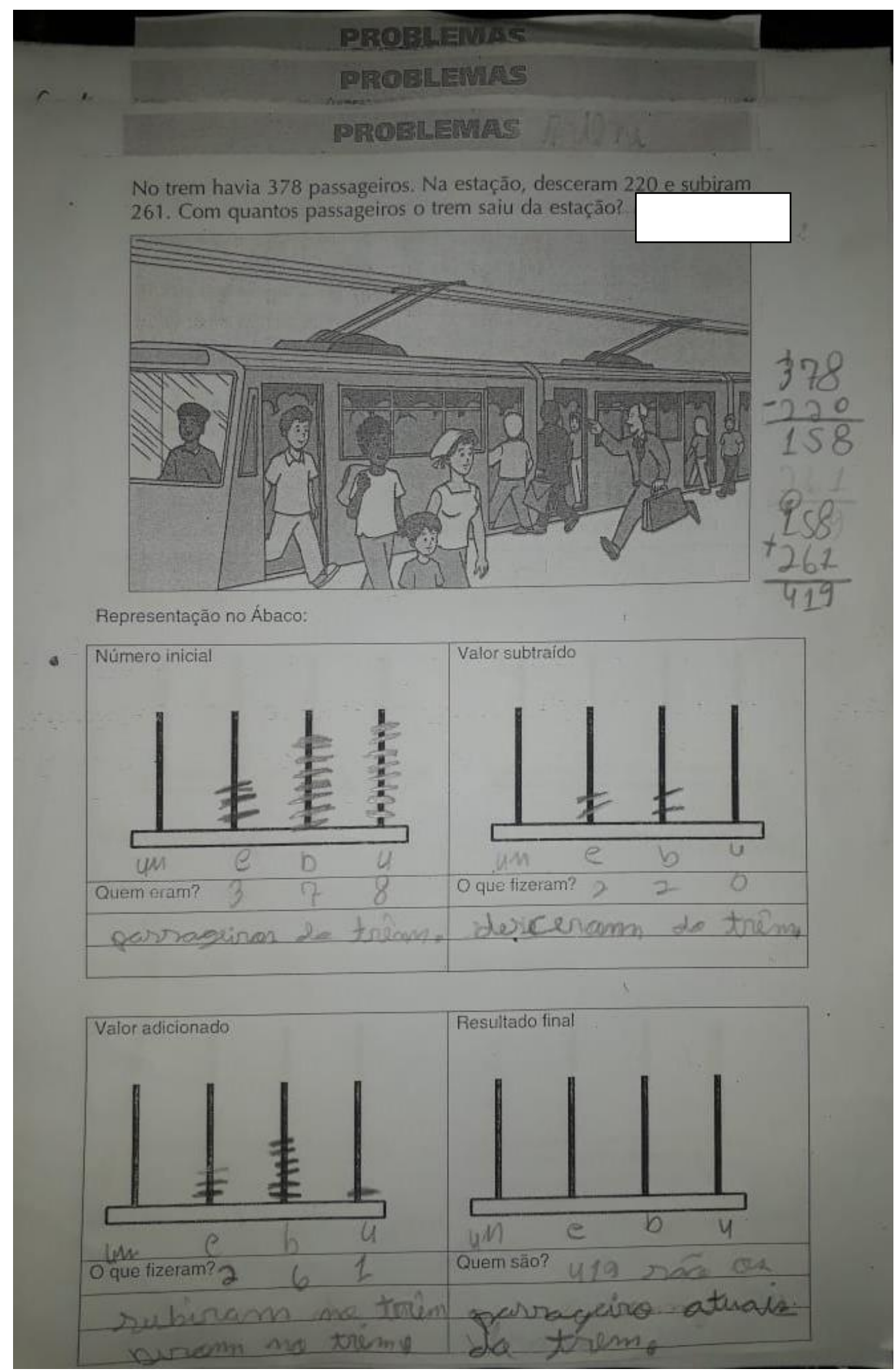

Fonte: Adaptado de Imenes; Jakubovic; Lellis (2000, p. 99). 
CRUZ, Alan Raniel Borges; TEODORO, Gisele de Fátima; BONUTTI, Viviane Aparecida. O uso do 24 ábaco no ensino das operações de adição e subtração: um relato de experiência com alunos do ensino fundamental

\section{Exemplo 2}
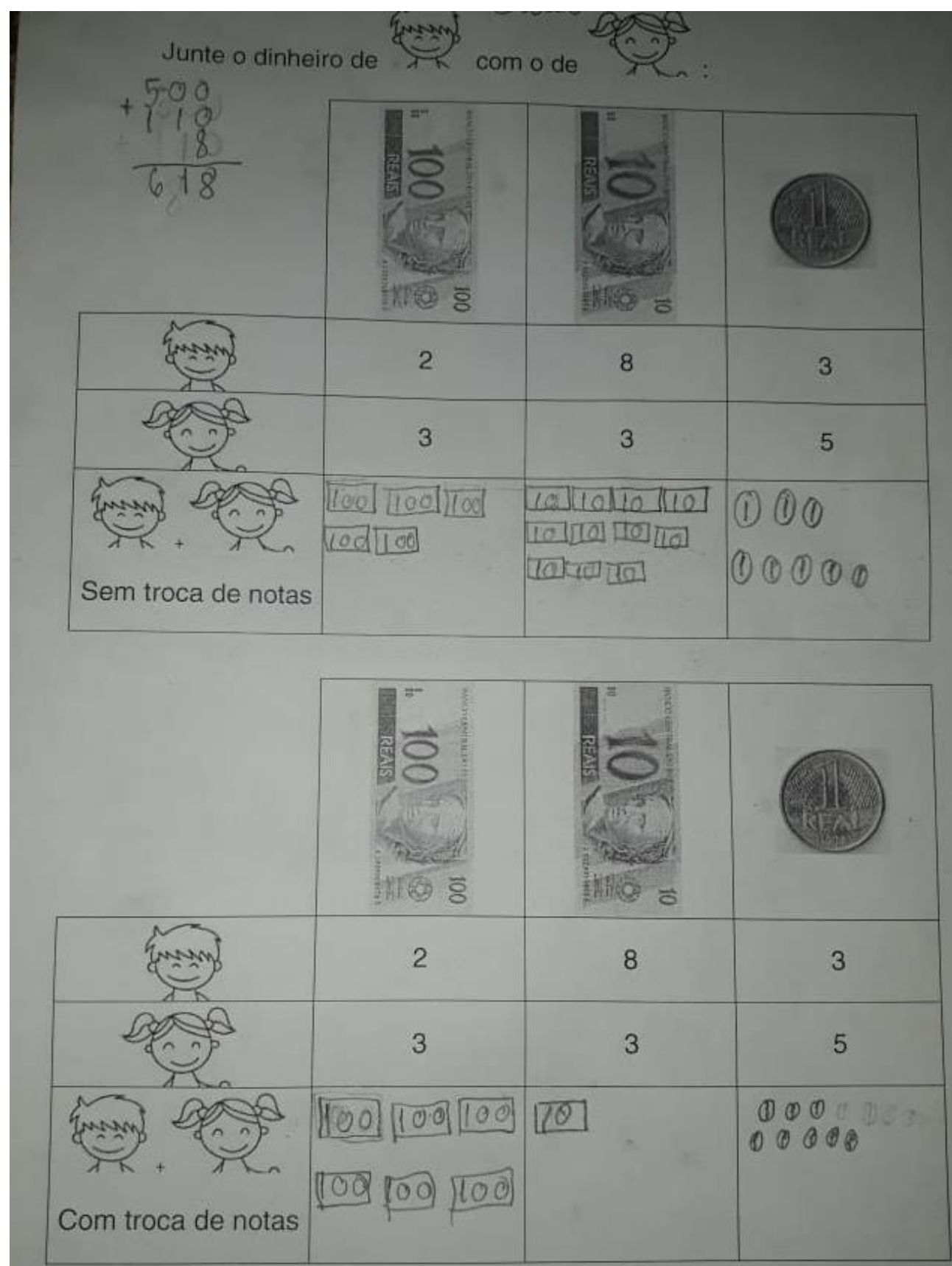

Fonte: Adaptado de Imenes; Jakubovic; Lellis (2000, p. 97). 


\section{Alan Raniel Borges Cruz}

E-mail: alan_raniel@yahoo.com.br

Currículo Lattes: http://lattes.cnpq.br/0543062753314902

Graduação em matemática pela PUC MINAS, graduação em física e pedagogia pela

Universidade Metropolitana de Santos (UNIMES).

Especialização em Ensino de Ciências por investigação Universidade Federal de Minas

Gerais (UFMG). Especialização em novas tecnologias para ensino da matemática

Universidade Federal Fluminense (UFF).

Diretor de escola pública, com cargo original de Professor de Matemática na rede municipal de Betim.

\section{Gisele de Fatima Teodoro}

E-mail: gisele.fatima.teodoro@gmail.com

Graduação em matemática pela PUC MINAS

Professora de Matemática na Prefeitura Municipal de Contagem

\section{Viviane Aparecida Bonutti}

E-mail: vivianebonutti@yahoo.com.br

Graduação em matemática pela PUC MINAS 